\title{
Rare association of tetralogy of Fallot with absent pulmonary valve syndrome with anomalous origin of right pulmonary artery from ascending aorta
}

\author{
Niraj Nirmal Pandey, Arun Sharma, Sanjeev Kumar
}

Department of Cardiovascular Radiology and Endovascular Interventions, All India Institute of Medical Sciences, New Delhi, Delhi, India

Correspondence to Dr Arun Sharma,

drarungautam@gmail.com

NNP, AS and SK contributed equally.

Accepted 18 August 2018

\section{DESCRIPTION}

A 2-month-old boy presented to the paediatric cardiology department with cyanosis and feeding difficulties. Chest radiograph revealed cardiomegaly, right-sided aortic knuckle and dilated pulmonary artery segment along with mild indentation on the lower trachea and diffusely narrowed left main bronchus (figure 1A). A diagnosis of tetralogy of Fallot (TOF) with absent pulmonary valve syndrome was made on transthoracic echocardiogram; however, origin of right pulmonary artery (RPA) was not well visualised. The patient further underwent CT angiography (CTA) to delineate the cardiac as well as any extracardiac abnormalities.

CTA revealed features of TOF with pulmonary annular stenosis. Pulmonary valve leaflets were absent with aneurysmal dilatation of the main and left pulmonary artery (LPA) (figure 1B). The RPA was not seen in continuation with the main pulmonary artery; instead, it was seen to arise from the mid-ascending aorta and supplying the right lung (figure 1C). Review of the lung window images revealed collapse of the apicoposterior segment of the left upper lobe and superior segment of the right lower lobe (figure 1D). Subsequent careful examination of the airway depicted an 'inverted-V'-shaped trachea with diffuse mild narrowing of the left main bronchus, near-complete occlusion of the apicoposterior branch of the left upper lobe bronchus and the superior segmental branch of the left lower lobe bronchus, due to compression by the dilated left pulmonary artery (figure $1 \mathrm{E}-\mathrm{G}$ ). These findings were exquisitely demonstrated on virtual bronchographic images (figure $1 \mathrm{H}, \mathrm{I}$ ).

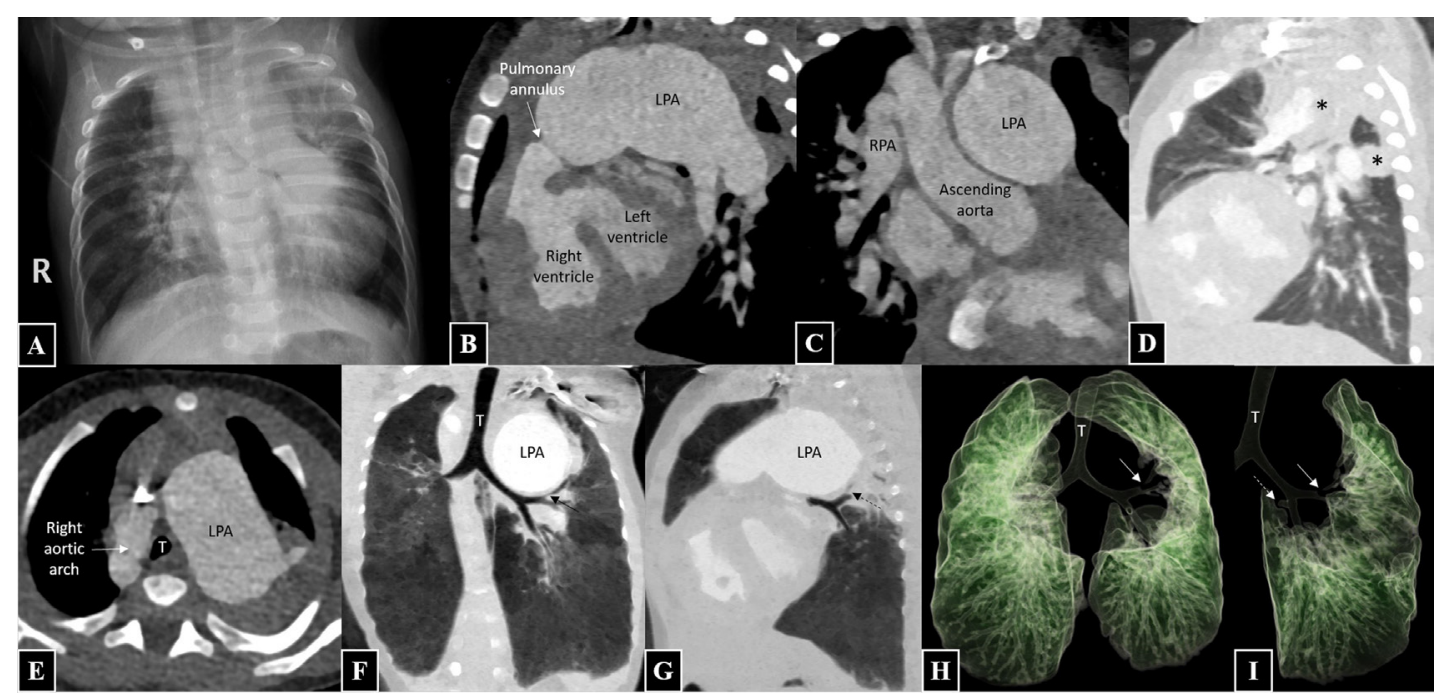

Figure 1 Frontal chest radiograph (A) reveals cardiomegaly, right-sided aortic knuckle and dilated pulmonary artery segment along with mild indentation on the lower trachea and diffusely narrowed left main bronchus. Sagittal oblique maximum intensity projection (B) shows presence of features of tetralogy of Fallot, that is, right ventricular hypertrophy, perimembranous ventricular septal defect and pulmonary annular stenosis. Pulmonary valve leaflets are not seen with aneurysmal dilatation of the main and left pulmonary artery (LPA). Coronal oblique maximum intensity projection (C) shows right pulmonary artery (RPA) arising from the mid-ascending aorta. Sagittal multiplanar reconstruction (D) reveals collapse $\left(^{*}\right)$ of the apicoposterior segment of the left upper lobe and superior segment of the right lower lobe. Axial image at the level of arch (E) shows 'inverted- $\mathrm{V}$ '-shaped trachea between the right aortic arch and the dilated LPA. Coronal multiplanar reconstruction lung window (F) reveals diffuse mild narrowing of the left main bronchus due to compression by the dilated LPA with near-complete occlusion of the apicoposterior branch of the left upper lobe bronchus (black arrow). Oblique sagittal multiplanar reconstruction lung window (G) reveals near-complete occlusion of the superior segmental branch of the left lower lobe bronchus (dotted arrow). Virtual bronchography images $(\mathrm{H}, \mathrm{I})$ show near-complete occlusion of the apicoposterior branch of the left upper lobe bronchus (black arrow) and the superior segmental branch of the left lower lobe bronchus (dotted arrow). 
Hemitruncus is a rare defect, accounting for only $0.12 \%$ of all congenital cardiac defects. It is best described as one branch of pulmonary artery originating from the ascending aorta with the other branch coursing normally from the main pulmonary artery, which is in continuation with the right ventricle. Moreover, in TOF, anomalous origin of LPA is more common as compared with that of RPA. Similarly, absent pulmonary valve syndrome (APVS) is also seen in only about 3\%-6\% of all cases of TOF. ${ }^{12}$ Coexistence of both anomalies in the setting of TOF is understandably extremely rare. In the presence of this complex anomaly, both lungs are exposed to high volume and pressure load; the right lung will receive blood from the aorta at a high systemic pressure while the left lung receives the entire right ventricular output. ${ }^{3}$ A right heart catheterisation evaluating the pulmonary vascular resistance and its reversibility would help decide amenability to surgery. Also, APVS results in aneurysmally dilated pulmonary arteries, which often cause significant

\section{Learning points}

- Coexistence of tetralogy of Fallot with absent pulmonary valve syndrome and anomalous origin of right pulmonary artery from ascending aorta is extremely uncommon.

- In this condition, both lungs are exposed to high volume and pressure load as the right lung receives blood from the aorta at a high systemic pressure while the left lung receives the entire right ventricular output.

- Absent pulmonary valve syndrome results in aneurysmally dilated pulmonary arteries, which often cause significant airway compression that can be exquisitely depicted on virtual bronchography images. airway compression that can be accurately depicted on CT, especially reconstructed virtual bronchography images.

Early surgical repair should be performed to prevent development of irreversible pulmonary hypertension. A variety of surgical manoeuvres have been employed for repairing the artery with anomalous origin, including direct end-to-end anastomosis, interposition with a synthetic graft or a homograft patch and use of aortic flap. Concurrent complete repair of TOF with homograft placement between the right ventricle and main pulmonary artery may be performed. The aneurysmally dilated arteries may require a reduction angioplasty.

Contributors NNP has participated sufficiently in the conception of the idea, development of the intellectual content, design, writing and final approval of the manuscript. AS has participated sufficiently in the conception of the idea, development of the intellectual content, design, writing and final approval of the manuscript. SK has participated sufficiently in the conception of the idea, development of the intellectual content, design, writing and final approval of the manuscript.

Funding The authors have not declared a specific grant for this research from any funding agency in the public, commercial or not-for-profit sectors.

Competing interests None declared.

Patient consent Parental/guardian consent obtained.

Provenance and peer review Not commissioned; externally peer reviewed.

\section{REFERENCES}

1 Erdem A, Aydemir NA, Demir H, et al. Anomalous origin of one pulmonary artery branch from the ascending aorta: experience of our center. Turk Kardiyol Dern Ars 2010;38:411-5.

2 Aly AM, Reid DA, Jiwani AK, et al. Absent pulmonary valve syndrome with left hemitruncus. AJP Rep 2012;2:51-4.

3 Khajali Z, Mohammadzadeh A, Khayatzadeh M. Anomalous origin of the right pulmonary artery from the ascending aorta accompanied by absent pulmonary valve syndrome and right-sided aortic arch: a rare case in adult congenital heart disease. Cardiol Young 2015;25:794-6.

Copyright 2018 BMJ Publishing Group. All rights reserved. For permission to reuse any of this content visit

http://group.bmj.com/group/rights-licensing/permissions.

BMJ Case Report Fellows may re-use this article for personal use and teaching without any further permission.

Become a Fellow of BMJ Case Reports today and you can:

- Submit as many cases as you like

- Enjoy fast sympathetic peer review and rapid publication of accepted articles

- Access all the published articles

- Re-use any of the published material for personal use and teaching without further permission

For information on Institutional Fellowships contact consortiasales@bmjgroup.com

Visit casereports.bmj.com for more articles like this and to become a Fellow 